DOI:10.24193/tras.52E.1

Published First Online: 2017/10/31

\title{
ISOMORPHIC DIFFUSION \\ IN PUBLIC SECTOR: \\ FOCUS ON CHINA
}

\author{
Cheng CHEN \\ Shangxin $\mathrm{CHI}$
}

\section{Cheng CHEN}

Associate professor, Department of Urban Management, School of Political Science and Public Administration, Huaqiao University, Quanzhou, Fujian, China

Tel.: 00861-516-033.9121

E-mail: chen4767@outlook.com

Shangxin $\mathrm{CHI}$ (corresponding author)

Associate professor, Department of Sociology, College of Psychology and Sociology, Shenzhen University, Shenzhen, Guangdong, China Tel.: 00861-501-947.8116

E-mail: chishangxin@126.com distance within different time and space. With data for a sample of 238 prefecture level cities collected from China, the authors aim to explore the correlation between isomorphism diffusion and spatial distance.

The results of the analysis suggest that local governments will be at a disadvantage if these are stated in a further location when isomorphic diffusion takes place. Moreover, the correlation between isomorphic diffusion and spatial distance varies according to the different phases of the diffusion process. The effect of geographical distance is initially strong in the growth period, but weakens later. The results will build bridges on isomorphic and geographical distance within diverse time and space in China, and have implications both theoretically and practically.

Keywords: isomorphic diffusion, geographical distance, public service centers, China. 


\section{Introduction}

Isomorphism has been noticed since Max Weber's bureaucratic structure was applied and diffused into all kinds of institutions. Weber firmly believed that the reason for organizational similarity must be attributed to the efficiency and power of bureaucracy, which have once been established and the impact could never be reversed. With decades passing by, people have hardly doubted the motivations behind institutional 'similarity' until DiMaggio and Powell (1983) argued that 'organizations are still becoming homogeneous' even if 'bureaucratization and rationalization have changed'. So what makes institutions so similar? They claimed that the impetus of bureaucracy's efficiency and power could be categorized into competitive types, which were probably applied at the early stage of isomorphism. However, the main factors that organizations must take into account are other organizations, which, on the other hand, gave credit for institutional factors.

Meanwhile, the concept of institutional isomorphism and three mechanisms intermingled during the whole process are also developed in this paper. The three mechanisms include: coercive isomorphism (which originates from power and legitimacy), mimetic isomorphism (which derives from uncertainty) and normative isomorphism (which is associated with professionalization) (DiMaggio and Powell, 1983).

Scholars' thoughts diverged referring to motivations of isomorphism. Babones (2013) mentioned that isomorphism takes place either through emulation (a macro-phenomenological mechanism) or through coercion (a macro-realist mechanism). Beckert (2010) stated that competition should be included as a fourth mechanism, which was not mentioned in DiMaggio and Powell's initial researches. Furthermore, Beckert (2010) noticed that alongside an overemphasis on time, it is widely believed that organizations are deemed to reach convergence, and the four mechanisms can support the processes of institutional divergence as well.

Nevertheless, Pollitt (2001) categorized isomorphism into two theoretical approaches, the functional approach and the constructive approach. Firstly, the functional approach emphasizes that the convergence occurs by the functional imperatives of efficiency, or evaluating consequences in terms of prior preferences; convergence is more about legitimacy and symbolism rather than measured performance. Secondly, the constructive approach emphasizes more on acting appropriately than maximizing the efficiency or the effectiveness. Meyer et al. (1997) envisaged a new island that will experience isomorphism, decoupling, as well as expansive structuration, pointing out that both realism and micro-realism can hardly explain this phenomenon. According to the researchers, a nation-state is culturally constructed and embedded rather than a rational actor; it is the worldwide culture that formulates the world-society models which, in turn, shape the identities, structures, and behaviors of the nation-state (Meyer et al., 1997). Zhou (2004) divided the organizational environment into two parts, which are the technological environment and the institutional environment. The technological environment puts an emphasis on efficiency and effectiveness (Comin, Dmitriev and Rossi-Hansberg, 2012), while the institution- 
al environment focuses on acceptance, rationality, justification and legality of the law, culture, regulations and institutions (March, Schulz and Zhou, 2000).

No matter what the composition of the dynamic system of institutional isomorphism is, all the researches mentioned above were primarily based on DiMaggio's and Powell's three-mechanism frame. People can virtually understand isomorphism from different kinds of aspects, which means that studies about institutions can be more profound. In the field of sociology, organizational isomorphism is defined as the resemblance of focal organization to other organizations in its environment, while in the field of innovation, institutional isomorphism can be judged as a certain kind of 'innovation diffusion', while people regarded innovation as the creation of new idea, new application, new product of service, or organization (Yeloglu and Sagsan, 2009). Among various diffusion models, the Bass model is recognized as the most widely used as it incorporates both innovative and imitative effects, which means adopters can be classified as innovators or as imitators while the speed and timing of adoption depends on the degree of innovativeness and the degree of imitation among adopters (Hsu and Mesak, 2005). Based on Bass's theory, Salomon and $\mathrm{Wu}$ (2012) applied a diffusion curve model to employment data for the 1984-2005 period and found that imitation has a much greater effect on diffusion than innovation itself. If we regard Bass diffusion model as a systematic one, which includes both internal and external effects, the 'theoretical replication' criteria used by Zhu (2014) could be applied to external influences operating in authoritarian China, namely 'mandatory' and 'championship' criteria. 'Mandatory diffusion' refers to the coexistence of vertical government intervention, while 'championship diffusion' refers to horizontal competition among local government officials. However, classic assumption about geographical proximity, competition and vertical intervention need to be modified (Zhu, 2014).

Jun and Weare (2011) simplified the contributory factors into two key dimensions: the level of decision and the goal of the organization. However, it should be noted that all previous researches were based on theory that involved three common clusters of factors: characteristics of innovation, characteristics of adopters, and the social system in which the adoption occurs. The three factors formed the key elements in diffusion research.

Institutional isomorphism can also be applied to the field of policy science, which is referred to as policy transfer, and is defined as a process in which knowledge about policies, administrative arrangements, institutions and ideas in one political setting (past or present) is used in the development of policies, administrative arrangements, institutions and ideas in another political setting (Dolowitz and Marsh, 1996). According to Radaelli (2000), coping policies or organizational structures are not driven by efficiency considerations; rather, they are a way of securing legitimacy in political life, which is considered to be a broad, multilevel concept and can be examined on a macro level or micro level. Deephouse (1996) examined this proposition by checking the relationships between strategic isomorphism in commercial banks and public, regu- 
latory endorsement, and found that isomorphism is related to legitimacy conferred by bank regulators and media, even in the presence of organizational age, size, and performance.

From the aforementioned studies it can be concluded that the perspectives have commonalities, despite their different heritages and disciplines. In institutionalism, isomorphism takes place only as a result of uncertainty of circumstances as organizations have no choice but to emulate others, in the hope of minimizing risks in the future; organizations adopted innovation just because 'others adopted [it] already', which implied that higher adoption rates would accelerate the diffusion pace (Frumkin and Galaskiewicz, 2004).

In terms of policy science, it seems that public organizations focus on legitimacy more than private institutions (Weatherford, 1992) because company performance can be easily measured by profits while the measurement of government performance is far more complex and cannot be evaluated by means of data and formulae alone. Some scholars used public interest as criteria, but these criteria itself could never be standardized, which signified uncertainty surrounding the position of public organizations and a higher risk of government innovation. In such circumstances, it is a better strategy to do what others do (which is known as 'mimetic' or 'diffusion adoption') in order to gain legitimacy.

Presumably, it is reasonable to say that public-sectors organizations are more sensitive to the external environment, and that there is more scope for such organizations to emulate pivot institutions, compared with for-profit organizations. However, public sector organizations used to be recognized as central actors propelling institutional convergence, both as promoters of coercive isomorphism, and as regulators ensuring legitimacy. Few studies, however, have conceptualized public sector organizations as research objects. Furthermore, public sector organizations are more vulnerable to circumstances, which means they adopt certain kinds of structures, processes or innovations in order to benefit from the advantages that mimetism offers. It could be said that mimetism is virtually the same process as innovation diffusion, and refers to the concept that a product, idea, process or structure that used to be applied in one institution is now emulated in other institutions.

The whole process of diffusion can be divided into a variety of adoptions, and each adoption itself can be identified as a process, which is formed by five stages: knowledge, persuasion, decision, implementation and confirmation (Rogers, 1983). During the knowledge stage, most organizations are initially exposed to an innovation, which means that the more information they acquire about an innovation, the more likely that they will become early adopters. In the persuasion stage, organizations that are interested in innovation will actively seek related information. The decision stage is defined by Rogers (1983) as the most difficult stage on which to acquire empirical evidence; again, this kind of evidence mainly depends on the amount and content of information gained. In the implementation stage, organizations still need further information before a decision can be made to fully implement a particular in- 
novation or not to use it. Finally, in the confirmation stage, the organization finalizes its decision to continue using the innovation. In any case, all the stages have been closely linked to information, and the essence of innovation diffusion can be recognized as the flow of information. According to Hsu and Mesak (2005), information flow refers to the movement of information from one place to another, while information about an innovation cannot be evenly distributed; some places acquire information more rapidly than others (Hsu and Mesak, 2005). Many researches have focused on adoption units or organizations as independent units. As a result, such studies have attempted to link institutional isomorphism to institutional characteristics, such as socio-economic factors, development experience, and human capital. As information that is greatly demanded by adopters always starts with interactions with other agents, especially innovators or early adopters, this particular research totally disregarded the interactions that occur between institutions within the diffusion process, even though the frequency and success of innovation diffusion is usually shaped by geography. Information is easily transmitted between institutions that are in close proximity to each other rather than located far apart.

To explore this mechanism, we have attempted to reveal the occurrence of isomorphism, which is mediated by distance. Although the concept of isomorphism can be applied to an organization or a process, an innovation can be interpreted as an idea, a process, a product or an organization. In this paper, we have conceptualized innovation as an institution; in particular, we conducted an empirical study of institutional isomorphism across time and space.

The mechanism underlying institutional isomorphism can be complicated, may differ from time to time, or even from place to place. The task of assimilating information about structures and processes in existing institutions is seemingly difficult; nonetheless, by observing the development of organizations from nil into existence, we can easily distinguish the similarities and differences between them, and explore the driving force for institutional isomorphism or heteromophism.

In this paper, we have described the whole development process of an administrative service center after examining the data obtained from prefecture-level cities in China. After applying an S-shape curve model over the course of 15 years, we divided the diffusion process into four stages. Our aim was to understand the relationships between institutional isomorphism and distance. Which is the best way of measuring the distance between different cities, and of measuring the differences between geological, economical, financial or political aspects? Do they play the same role at different stages? Are there any corresponding policies or measures that Chinese governments can take to allow isomorphic diffusion progress? By gathering data, explaining variables and running regression models, this research aimed to solve the above mentioned problems. 


\section{Data and methods}

Transitions in governance have taken place in China since the 1990s in the sense that Chinese governments have been trying to become limited and not unlimited, of laws and not of men, of transparency and not black box operation. Some scholars have identified the following characteristics of good governance principles: legitimacy, transparency, accountability, rule of law, responsiveness, effectiveness, civic participation, stability, cleanness and justice (Wang and Guo, 2015).

Against this backdrop, a local government innovation campaign has been conducted by the Central Compilation and Translation Bureau, together with the Central Party School and Peking University since 2000, whose initiative was to emulate reforms and consolidate innovations. This competition was judged on various criteria, including innovation, participation, effectiveness, importance, efficiency and diffusion. The public service center was unanimously awarded the top prize, although with different forms: some of the centers were commanded for their advanced working mechanisms (e.g., Haikou, which won the Finalist Award in 2000 owing to its direct-handling system, one-window service system, and service commitment system), while others had superior institutions (e.g., Nanjing, which was commended for its pioneering of a political affairs supermarket in 2000).

The idea of a public service center developed from the concept of a one-stop service, which was designed to provide company end-to-end services in commercial activities. During the years of Thatcherism, this concept of one-stop service was introduced in the field of administrative reforms to eradicate extreme examples of malpractice (such as organization inflation, poor efficiency and departmental fragmentation) which existed inside traditional bureaucracy and was hard to overcome. By gathering all related approved services into one place, a higher degree of efficiency and quality of public service can be expected, as this structure dispenses with the need to rotate between different departments or endure lengthy waiting times for services ${ }^{1}$.

On the other hand, it is easy to understand that gathering items requiring administrative approval into one hall will greatly enhance the efficiency, effectiveness and convenience of public service, which can be viewed as government process re-engineering or mechanism reform. But above all, the process of reform or innovation would result in a bottleneck if it is not accompanied by institutional reforms. Previously, the administrative approval system was substantially fragmented with various

1 A public service center is like a window, or rather a concentration of the government, which provides varieties of services for enterprises and citizens, including property registration, social security service, economy services, etc. People had to go back and forth from one organization to another until these services were gathered in one place. For example, take unemployment claim: previously, the laid off had to set up appointments with a career services center, and then draw unemployment benefit from social security institution. Nowadays, they can solve their problems by going to one place: a public service center. 
administrative approval items as well as diffusible approval sectors, which means asymmetric information between core actors and executors. On the other hand, executors would be likely to resist any kind of reform or change in view of their vested interests and path dependence; for another, core actors could not transfer approval authority from one sector to another. On this account, the public service center was put forward as an institutional device that aims to instigate institutional innovation without affecting the substantial power of its exactors.

A public service center is a particular type of innovation, which is not only related to the public sectors' workflow, but is also concerned with institutional device. In 1999, Jinhua centralized 46 administrative approval authorities into one hall, which could be regarded as the embryonic form of municipal business hall. The seemingly simple measures were to exponentially increase administrative efficiency ex post, which enabled Jinhua to get a $\$ 2$ million prize from Zhejiang provincial government; then the mode of Jinhuawas promptly popularized all over Zhejiang Province. Afterwards, in September, 1999, the first institution (which is known as the official Administrative Approval Centre) was established in Shangyu, Zhejiang Province, with a specialized managerial structure, independent personnel system and intact administration system.

\subsection{Diffusion of Jinhua model}

This research attempts to faithfully recall the development path of administrative service centers by recording their establishing time. A purposive non-probabilistic sampling method is applied to the research.

Up until now, a significant number of administrative service centers have been set up within different provinces, cities and counties. It is conceivable that diverse organizational ownerships and forms coexist because of the difference between history, economic background, or social status. Some of the organizations are representative offices of government, while others perform the role of constituent departments or public utilities, within the approval of municipal people's governments. Some of them are called Administrative Approval Centre or Citizen Convenience Centre, whereas others are known as public administrative service center or government affairs hall. Whatever formation an organization is, it is essential to have a few distinctions between different institutions, depending on the organizational functions and job contents. All the organizations as mentioned above are designed to provide fast, transparent, and one-stop services for enterprises and citizens within their local jurisdiction area.

Furthermore, referring to the interior structure and mechanism, almost all the centers share the same binary model, which can be regarded as one of the main differences from other bureaus. Two hierarchic levels coexist within the whole system. The first level is the management level, which is constituted of a coordination unit, inspection bureau, comprehensive office and investment agency, where all the staffs' personnel records are transmitted into the institution. And the second level is the ser- 
vice level, which is formed by the staffs whose organizational affiliations still remain in their original unit except for membership credentials.

For the timing of service center adoption, we rely primarily on internet surveys by means of entering keywords such as 'administrative service center' 'administrative approval center' 'government affairs hall', 'launch', 'establish' and 'operate'; we search for the information by combining the keywords together with the names of the prefecture-level cities. We applied this method to identify the names of the service centers in every prefecture-level city in China. Besides, from the websites as well as direct phone calls with the service centers, we acquired information about their dates of foundation. A considerable number of these data were collected from the introduction information on the homepages of their official websites; others were from various resources including news reports, interviews or yellow pages, which show the details about the history since the centers have been established, enabling us to determine the year of adoption since 1999.

Furthermore, sometimes, the time when an administrative service center was launched is not exactly the same as the time when it is put into operation. For instance, Jinhua, which was established in 1999, was reconstructed in September 2001. In addition, due to the contradictions between the steeper growing rate of the economy and limited working space, the institution which was built previously could hardly meet current needs. In March 2007, they moved from the government building to a new building which was put into operation in April, 2007. Since we focus on the time when an organization initially got established, we chose the earliest date as the sample.

Ultimately, 234 samples are collected from 1999 until 2014. Almost every prefecture-level city is included except for Urumqi and Karamay, which have not established their substantiated service centers yet. Bases on the sample, we made a graph with the vertical being the cumulated proportion of adopters, while the abscissa being the adoption time; the whole diffusion process can be described as the sigmoid ${ }^{2}$ curve, depicted in Figure 1.

In figure 1, the abscissa refers to the time that the prefecture-level city adopted a service center. Jinhua established a service center in January 1999, while Zhongshan accepted diffusion in June 1999; then we mark diffusion time for Jinhua as 0 and for Zhongshan as 5. The same goes for other cities. Ordinate refers to the proportion of service centers accepted by prefecture-level cities. We divided the cumulative adopted number by the total number (234). Zhongshan for example adopted isomorphism diffusion in June 1999; theretofore only Jinhua had set up a service center. Therefore the proportion for Zhongshan is $2 / 234=0.0085$. Consequently, the coordinates for Jinhua and Zhongshan are (0, 0.0043), (5, 0.0085).

2 The S-curve model, which was firstly investigated by Rogers (1983), can be divided into four distinct user segments and phases and categorized as: the formative phase, the growth phase, the maturity phase and the petrify phase (or shakeout phase) (Clusters, 1998). 


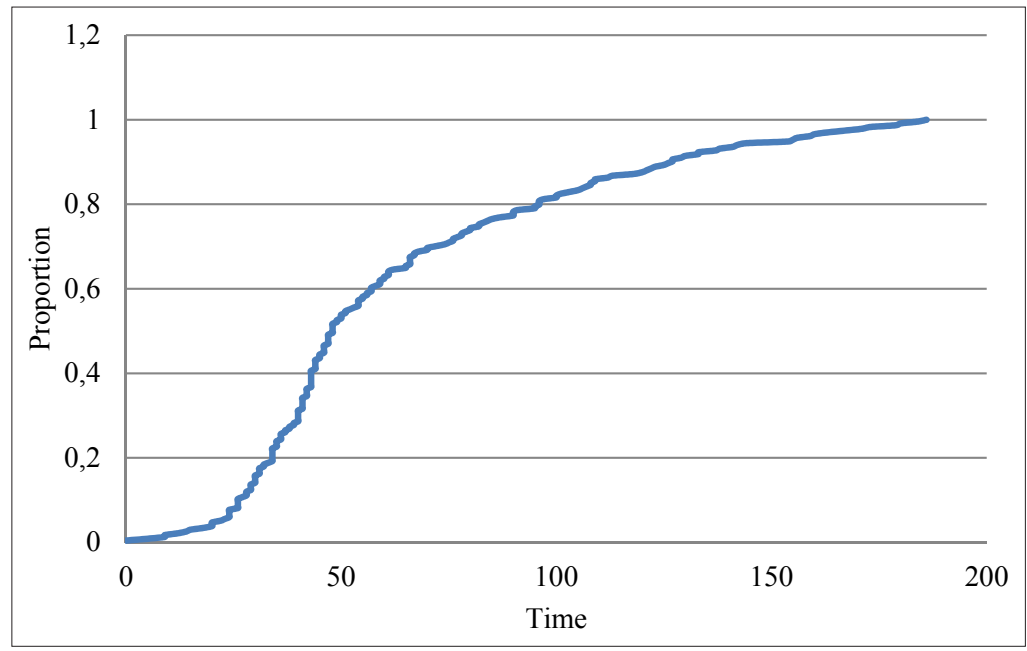

Figure 1: Isomorphic diffusion process

Source: Author's compilation

\subsubsection{The formative phase (1999-2000)}

In the initial period, due to the lack of clear theoretical directions, standard working patterns, as well as the essential basis of policies and law, the service centers usually worked as temporary arbitration organizations of provisional government, whose mission is just as simple as what is described in its name, 'Investment Service Centre'. Still, their first signs of competitiveness caught people's attention; references to higher efficiency and effectiveness are found through the news media and in the word of mouth. Therefore, there should be higher possibilities to establish centers because of the geographic proximities, compared with other regions. Evidence can be easily found from provinces such as Jiangsu, Jiangxi, and Anhui. They share borders with Zhejiang Province, which applied this structure in the formative period.

However, since it functions as the pilot stage for the service center, everything is under construction and few samples can be emulated and learned from. As a result, internal motivations would play a more critical role in this phase.

\subsubsection{The growth phase (2001-2003)}

Since 2000, all levels of governments have been promoting reforms of administrative approval and examination. All the administrative licensing items, policies, laws and regulations were sorted out at that time, followed by a large number of approval items eliminated and streamlined accordingly. At the end of 2000, the government of People's Republic of China proclaimed an announcement asking for the transparency of governmental affairs of all town governments. At the same time, it claimed for governmental transparency for all prefectural cities. Therefore, almost all the service centers established at this period are known as 'public affairs' or 'public affairs ser- 
vice center'. In 2001 the State Council issued the Advice on Implementing the Reform of the Administrative Examination and Approval System.

Because of the high efficiency of public media, the service centers expanded and were acquainted by more local governments. Most or even all administrative affairs were drawn into the centers, and some prefectural centers in Jiangxi, Jiangsu, Zhejiang, Anhui and Sichuan were set up during these years. Neighbor effects can be easily noticed when discussing the border regions. As there should have been more cases and pivot for reference, compared with the initial stage, the mimic mechanism would become one of the most essential elements at that time.

\subsubsection{The maturity phase (2004-2006)}

In 2004 the State Council promulgated an outline to comprehensively promote the administration in accordance with law program and law of administrative licensing, followed by a series of rules and regulations. These documents would lead to at least three consequences. Firstly, according to Article 25 in Law of Administrative Licensing, 'Upon approval of the State Council, the people's governments of the provinces, autonomous regions and municipalities may decide one administrative organ to exercise the power of administrative license of the relevant administrative organs according to the principle of simplification, unification and efficiency'. This statement obviously provided legitimate proofs for the existence of the service centers.

Although the legitimacy for service centers still had a long journey to go, new laws and regulations could be regarded as symbols that the development of the centers had transformed from the bottom-up model into the top-down one. Firstly, although institutional divergence still exists in the service centers, it is assumed that standardization and institutional isomorphism would be the tendency, aiming to consolidate the fragmented administrative service system. Secondly, with more participation and interference of national compelling force, it was coerce isomorphism rather than mimic mechanism or geographic proximity that might have become dominant at that time.

\subsubsection{The metamorphosis phase (2007-2014)}

It would be better to call it 'metamorphosis phase' instead of 'petrify phase' because from the aspect of technological innovation diffusion, crowding effect and diminishing marginal utility coexist due to the contradiction between supply and demand despite of imitation factors. However, the diffusion process in organizations may occur in a completely different way. For one thing, there can be at most 236 service centers because one prefectural city only needs one institution while other kinds of diffusion or isomorphism will probably experience a declining process as there seems to be no precise point of saturation for private sectors. For another, as suggested by previous studies, public sectors deemed to be much more sensible to circumstances and legitimacy. Laws and regulations, which exert the function as the coercive power, can be seen in the last stage, when the diffusion period moves into a completely new phase instead of shakeout over time. 
In 2007, after issuing several opinions of the State Council to strengthen the service industry, massive regulations were released in that year, including Opinions on Accelerating Pilot Work for Service Standardization, which accordingly, enabled the standardization of service center to be fully carried out in Shandong, Anhui, Jiangsu and Jiangxi Provinces. After prompting the understanding towards new environment, re-positioning and evaluation on the development status, all the centers rebuilt their hospitality services, windows circumstances, licensing processes to realize the goal of standardization.

From the aspect of diffusion, the process of standardization can be recognized as some kind of re-invention, which prevents the whole diffusion process from depression and maintains its sustainable development. In addition, from a sociological aspect, if divergence and convergence coexisted in previous stages, standardization would undoubtedly enhance institutional isomorphism; within this period it is a normative mechanism, neither coercive nor mimic isomorphism, that would dominate this process.

\subsection{Measuring proximity}

Distance can be measured in a set of multidimensional measures, including economic, financial, political, administrative, cultural, demographic, and global connectedness as well as geographic distance. Speaking of dimensions of distance, most of them refer to difference; for example, the economic distance stands for the differences in economic development and macroeconomic characteristics; the financial distance refers to the differences in financial sector development; the demographic distance means the differences in demographic characteristics; and knowledge distance implies for the difference in patents and scientific production (Berry, Guillen and Zhou, 2010).

In this paper, we only use geographic distance as the independent variable, namely, the spatial distance between prefectural cities and adoption leaders. In this case, the leader is Jinhua city. We computed the distance between two cities in miles for flying distance - air-miles.

\subsection{Models}

The empirical research analyzes the relationships between the distance and isomorphism in order to explore which phase would be more easily affected by geographical proximity, and in which direction the effects would take place; our goal is to see which kind of distance can explain the additional variance in these four stages.

Our dependent variables are time of isomorphism and the four stage time variables. The hypothesis is that different kinds of distance should have different effects on isomorphism diffusion. Furthermore, we believe that among these four periods, geographical proximity is the most important factor at the growth stage. We examined the directions of these effects. The following equation is the general statistical model applied to test the models: Isomorphism $=\mathrm{b}_{0}+\mathrm{b}_{1}{ }^{*} \mathrm{GD}+\mathrm{b}_{2}{ }^{*} 2^{\text {nd }}$ industry $+\mathrm{e}$. 


\section{Results}

Our sample for the isomorphism of public service center adoption includes 236 prefectural-level municipalities with complete data. Table 1 presents the frequency distribution by year of adoption for these prefectural-level cities being studied in this research. County-level cities and municipalities are excluded due to data deficiency.

Table 1: Isomorphism adoption by year

\begin{tabular}{|c|c|c|c|c|}
\hline & Year & $\begin{array}{c}\text { Number } \\
\text { of adopters }\end{array}$ & $\begin{array}{c}\text { Cumulative number } \\
\text { of adopters }\end{array}$ & $\begin{array}{c}\text { Number } \\
\text { of potential adopters }\end{array}$ \\
\hline \multirow{2}{*}{$\begin{array}{c}\text { Formative phase } \\
(1999-2000)\end{array}$} & 1999 & 4 & 4 & 236 \\
\hline & 2000 & 9 & 13 & 232 \\
\hline \multirow{3}{*}{$\begin{array}{l}\text { Growth phase } \\
(2001-2003)\end{array}$} & 2001 & 43 & 56 & 223 \\
\hline & 2002 & 59 & 115 & 180 \\
\hline & 2003 & 30 & 145 & 121 \\
\hline \multirow{3}{*}{$\begin{array}{l}\text { Maturity phase } \\
(2004-2006)\end{array}$} & 2004 & 18 & 163 & 91 \\
\hline & 2005 & 15 & 178 & 73 \\
\hline & 2006 & 8 & 186 & 58 \\
\hline \multirow{8}{*}{$\begin{array}{l}\text { Metamorphosis phase } \\
\quad(2007-2014)\end{array}$} & 2007 & 11 & 197 & 50 \\
\hline & 2008 & 7 & 204 & 39 \\
\hline & 2009 & 10 & 214 & 32 \\
\hline & 2010 & 6 & 220 & 22 \\
\hline & 2011 & 3 & 223 & 16 \\
\hline & 2012 & 5 & 228 & 13 \\
\hline & 2013 & 3 & 231 & 8 \\
\hline & 2014 & 3 & 234 & 5 \\
\hline Total & & 236 & & 2 \\
\hline
\end{tabular}

Source: Author's compilation

\subsection{Pooled regression}

In Tables 2 and 3, the results are shown by running a regression for the full sample of cities. We start with testing the model including theoretically assumed variables to see whether it meets previous assumptions. This test rejects the null hypothesis that geography distance is irrelevant to isomorphic diffusion with a highly statistically significant Pearson coefficient, which indicates that the further the distance between cities and Jinhua is, the more likely cities will apply isomorphism at a later stage.

Table 2: Coefficients between spatial distance and isomorphic diffusion in 1999-2014

\begin{tabular}{lcc}
\hline Independent variable & $\mathbf{R}^{2}$ & $\mathbf{n}$ \\
\hline logAirmiles & 0.05 & 232 \\
\hline
\end{tabular}

Notes: * Statistically significant; ** statistically highly significant

Source: Authors' computations 


\subsection{The importance of geography in the four phases}

Since previous studies are all based on spatial dimension, we examined the impact of geographical distance and divide the whole diffusion process into the four phases (formative, growth, maturity and metamorphosis phases respectively). Table 3 presents the results examining the moderating impact of geographical distance. In accordance with the previous hypothesis, the positive coefficient on geographical distance interaction indicates that the correlations between spatial distance and isomorphic diffusion will be greatly weakened after the growth period. None of the interaction terms have a significant coefficient except for the second phase.

Table 3: Coefficients between spatial distance and isomorphic diffusion in the four stages

\begin{tabular}{lcccc}
\hline & Formative phase & Growth phase & Maturity phase & Metamorphosis phase \\
\hline $\log$ AirMiles & -6.868 & $8.399^{* *}$ & 6.231 & 4.359 \\
$\mathrm{R}^{2}$ & 0.155 & 0.065 & 0.015 & 0.002 \\
$\mathrm{~N}$ & 12 & 132 & 41 & 48 \\
\hline
\end{tabular}

Notes: * Statistically significant; ** Highly statistically significant

Source: Authors' computations

Some early adopters and innovators have set examples for other cities, so more information and opportunities with fewer risks are available in the growth period. Thus, it is mimetic mechanism that dominates this process, which means that the information will be one of the most important factors considered by the adopters. Furthermore, because geographical distance influences the acquiring of information to a great extent, there are strong connections between these two variables. These results systematically support our hypothesis despite low values of R Square.

\subsection{The importance of geography in three regions}

After illustrating the significance of geographic interactions in isomorphism adoptions, a question might be raised whether the region has any effect. As a result, all the cities in our sample are divided into three groups: the cities in eastern, central and western regions respectively. The classification was established at the Fourth Session of the Sixth National People's Congress, which was held in 1986 and a few minor modifications were made to it from 1997 to 2000. It is said that the regional economy has been gradually formulated on the basis of its individual geographic locations and the level of economic development. Accordingly, cities in the three regions all have their own characteristics. For example, as for the eastern region, the advantages of geographical location and abundant resources create a beneficial environment for the development of municipalities in this region, so most of the cities have become economic leaders in China. As for the central region, because it has the geographical advantage of linking the eastern and western regions together and a strong foundation of heavy industry, the region is the second developed region in this country. Finally, the western zone is located in the poorest area with complex topography. 
Therefore with relatively late development, there still has been an obvious gap between the western region and the other two regions, which means that there are still great opportunities and potential in its future development. The cities in these three regions are listed in Table 4.

Table 4: Three regions in China

\begin{tabular}{lrrl}
\hline \multicolumn{1}{c}{ Area } & $\mathrm{Km}^{2}$ & $\%$ & Provinces, municipalities and prefectural cities by region \\
\hline $\begin{array}{l}\text { Eastern } \\
\text { Region }\end{array}$ & 129.4 & 13.5 & $\begin{array}{l}\text { Beijing, Fujian, Guangdong, Guangxi, Hainan, Jiangsu, } \\
\text { Liaoning, Shandong, Shanghai, Hebei, Zhejiang }\end{array}$ \\
$\begin{array}{l}\text { Central } \\
\text { Region }\end{array}$ & 281.8 & 29.3 & $\begin{array}{l}\text { Shanxi (山西), Inner Mongolia, Jilin, HeiLongjiang, } \\
\text { Anhui, Jiangxi, He'nan, Hubei, Hu'nan, Guangxi }\end{array}$ \\
$\begin{array}{l}\text { Western } \\
\text { Region }\end{array}$ & 541.4 & 56.4 & $\begin{array}{l}\text { Sichuan, Guizhou, Yunnan, Tibet, Shanxi (陕西), Gansu, } \\
\text { Ningxia, Qinghai, Xinjiang }\end{array}$ \\
\hline
\end{tabular}

Source: Authors' computations

Table 5 reports the estimations of the sample of the three regions respectively. The impact of geographic distance on the isomorphic diffusion is not significant except for the central region, while for some poor cities in the western region a negative correlation between these two variables exists.

Table 5: Coefficients between spatial distance and isomorphic diffusion for three regions

\begin{tabular}{lccc}
\hline & Eastern & Central & Western \\
\hline $\log$ AirMiles & 23.328 & $51.037^{* *}$ & -3.675 \\
$\mathrm{R}^{2}$ & 0.027 & 0.136 & 0.000 \\
$\mathrm{~N}$ & 102 & 93 & 38 \\
\hline
\end{tabular}

Notes: * Statistically significant; ** statistically highly significant

Source: Authors' computations

The elements that have impacts on isomorphic diffusion in the eastern and western regions in China are various and complicated with low $\mathrm{R}$ squares for the three regions. But it is conceivable to expect that the spatial distance will have positive influence on adopters in the central region. The reason is that cities in this area are neither too poor nor too rich as the municipalities in other regions. On the one hand, for the poor cities, it is not decided by their willing but by their ability; to a great extent, financial problems have impact on many aspects. On the other hand, for the rich eastern cities, they do not have to be as energetic and innovative as the second-tier cities, because they have already been superior to most of the other cities. In a word, only the cities located in the central region will have motivations and probabilities to gather information, learn from other innovators and imitate advanced experiences. 


\subsection{Which is more important?}

The next step is to figure out which aspect really matters in geographical interaction, the region of cities or the adoption time? Considering that region matters, it means that the geographical distance would be significantly correlated with isomorphic diffusions within the central region no matter when the establishment takes place. On the contrary, if it is the adoption time that mainly has an impact, it implies that no matter where the city is located, there will be a significant correlation between the two variables. To investigate this possible dependence, we observe four phases within sample cities that are in different regions. Therefore, this exploration might provide reassurance that the geographic distance plays a dominant role in the samples of cities that are studied.

Table 6: Coefficients between spatial distance and isomorphic diffusion for regions and phases

\begin{tabular}{lccccccccccc}
\hline & \multicolumn{3}{l}{ Formative phase } & \multicolumn{3}{c}{ Growth phase } & \multicolumn{3}{c}{ Maturity phase } & \multicolumn{2}{c}{ Metamorphosis phase } \\
\cline { 2 - 12 } & Eastern & Central & Eastern & Central & Western & Eastern & Central & Western & Eastern & Central & Western \\
\hline logAirMiles & $-15.444^{*}$ & 19.568 & $12.055^{* *}$ & $18.433^{* *}$ & $58.461^{*}$ & -9.034 & -5.314 & 19.347 & -11.797 & 4.806 & 74.314 \\
$\mathrm{R}^{2}$ & 0.887 & 0.700 & 0.140 & 0.301 & 0.329 & 0.017 & 0.031 & 0.011 & 0.017 & 0.002 & 0.058 \\
$\mathrm{~N}$ & 5 & 5 & 56 & 60 & 16 & 16 & 13 & 12 & 25 & 15 & 8 \\
\hline
\end{tabular}

Notes: * Statistically significant; ** statistically highly significant

\section{Source: Authors' computations}

From the last column in Table 6, it is apparent that the spatial distance has a significant impact at the growth stage. However, this significant relation only exists in the second phase when referring to the central cities. We can make a bold conjecture that these two variables are significantly related not because the cities are located in the central part of China, but because they are implemented during the second process. Besides, there is significant relationship between the two variables in the whole process, because a majority of cities (56.4\%) adopt isomorphism in the second stage; it is the same when it comes to the central region because most public service centers in the central region were established in the growth period, which can be clearly observed in the cross tabulation presented in Table 7.

Table 7 shows that $64.5 \%$ of central cities participate in isomorphic diffusion in the second phase, $54.4 \%$ in the eastern region and $42.1 \%$ in the western region. As a result, these findings can be regarded as strong evidence that during the growth process it is particularly detrimental to be in a distant location from the adoption leaders. 
Table 7: Region * Phase Cross-tabulation

\begin{tabular}{|c|c|c|c|c|c|c|c|}
\hline & & & \multicolumn{4}{|c|}{ Phase } & \multirow{2}{*}{ Total } \\
\hline & & & 1 & 2 & 3 & 4 & \\
\hline \multirow{12}{*}{$\begin{array}{l}\text { 흥 } \\
\text { 또 }\end{array}$} & \multirow{4}{*}{ Eastern } & Count & 6 & 56 & 16 & 25 & 103 \\
\hline & & $\%$ within Region & $5.8 \%$ & $54.4 \%$ & $15.5 \%$ & $24.3 \%$ & $100.0 \%$ \\
\hline & & $\%$ within Phase & $46.2 \%$ & $42.4 \%$ & $39.0 \%$ & $52.1 \%$ & $44.0 \%$ \\
\hline & & $\%$ of Total & $2.6 \%$ & $23.9 \%$ & $6.8 \%$ & $10.7 \%$ & $44.0 \%$ \\
\hline & \multirow{4}{*}{ Central } & Count & 5 & 60 & 13 & 15 & 93 \\
\hline & & $\%$ within Region & $5.4 \%$ & $64.5 \%$ & $14.0 \%$ & $16.1 \%$ & $100.0 \%$ \\
\hline & & $\%$ within Phase & $38.5 \%$ & $45.5 \%$ & $31.7 \%$ & $31.2 \%$ & $39.7 \%$ \\
\hline & & $\%$ of Total & $2.1 \%$ & $25.6 \%$ & $5.6 \%$ & $6.4 \%$ & $39.7 \%$ \\
\hline & \multirow{4}{*}{ Western } & Count & 2 & 16 & 12 & 8 & 38 \\
\hline & & $\%$ within Region & $5.3 \%$ & $42.1 \%$ & $31.6 \%$ & $21.1 \%$ & $100.0 \%$ \\
\hline & & $\%$ within Phase & $15.4 \%$ & $12.1 \%$ & $29.3 \%$ & $16.7 \%$ & $16.2 \%$ \\
\hline & & $\%$ of Total & $0.9 \%$ & $6.8 \%$ & $5.1 \%$ & $3.4 \%$ & $16.2 \%$ \\
\hline \multirow{4}{*}{ Total } & & Count & 13 & 132 & 41 & 48 & 234 \\
\hline & & $\%$ within Region & $5.6 \%$ & $56.4 \%$ & $17.5 \%$ & $20.5 \%$ & $100.0 \%$ \\
\hline & & $\%$ within Phase & $100.0 \%$ & $100.0 \%$ & $100.0 \%$ & $100.0 \%$ & $100.0 \%$ \\
\hline & & $\%$ of Total & $5.6 \%$ & $56.4 \%$ & $17.5 \%$ & $20.5 \%$ & $100.0 \%$ \\
\hline
\end{tabular}

Source: Authors' computations

\section{Further discussions and conclusions}

The results presented in this paper have implications for both theory and practice. Firstly, our findings indicate that in order to comprehend the speed of diffusion, it is crucial to take geographic distance into account when understanding isomorphic diffusion. Researchers suggest that local governments are at a disadvantage when their locations are far during the process of isomorphic diffusion. This liability is due to unfamiliarity with institutional information. As such, it is better for central government to provide more information for those remote areas, especially in the growth phase. The reason for this is that it can be the most appropriate moment for governments in different locations to learn from each other. Furthermore, it is beyond our expectation that the economic development and the spatial diffusion are not highly correlated, which might lead to difficult implementations of policies because of inadaptability.

Secondly, although previous studies have been analyzing the isomorphic diffusion from the dimension of 'space', the model in this paper can be adapted well when referring to the dimension of 'time'. We separate the whole process into four stages including formative, growth, maturity and metamorphosis phases through observation, and then find the impacts of geographical distance change over time (for each phase). This implies that the influence of geography is initially strong in the growth period, but weakens later, and even decays over time.

This study provides worthwhile solutions to examine the government isomorphic diffusion across time and space, and we hope that the evidence on significance of spa- 
tial links with the isomorphic diffusion and the institutional approach in measuring distance will also be appropriate for future researches in some other fields.

The results highlight the impact of distance on strategy, thus offering further insights to practitioners. As geographic distance almost dominates the whole diffusion process, it is better for local governments (especially for those that are further away from superior ones) to communicate and gain information and experience as much as possible in order to eliminate potential deficiencies created by locations. Governments that are close to earlier adopters should seize their opportunities at the very beginning of the whole process; otherwise they will lose their advantages gradually.

Although there are three isomorphic mechanisms, this paper only concentrates on mimic isomorphism, which might explain the low $\mathrm{R}$ levels presented above. As China is a centralized bureaucratic state, it is the subordination to central authorities rather than effectiveness of policy that determine those prefectural officials' decisions, thus we can ask what is the relationship between 'isomorphism diffusion' and 'coercive isomorphism'? Is that an appropriate variable we can use to measure 'coercive isomorphism'? Furthermore, it is remarkable that 'normative isomorphism' plays such an important role in metamorphosis stage. There's no doubt that we can regard public service center standardization as another kind of innovation, but the mechanism of normative isomorphism cannot be omitted during the whole isomorphism diffusion process.

We hope that the basic ideas in this research will provide some experience and widen the mentality for future researches, and that other researches will further the studies based upon our findings by examining the interplay between distance, diffusion and strategies.

\section{References:}

1. Babones, S., 'The Global Diffusion of Inequality since 1970', 2013, [Online] available at https://ses.library.usyd.edu.au/handle/2123/9347, accessed on October 23, 2016.

2. Beckert, J., 'Institutional Isomorphism Revisited: Convergence and Divergence in Institutional Change', 2010, Sociological Theory, vol. 28, no. 2, pp. 150-166.

3. Berry, H., Guillen, M.F and Zhou, N., 'An Institutional Approach to Cross-national Distance', 2010, Journal of International Business studies, vol. 41, no. 9, pp. 1460-1480.

4. Comin, D.A., Dmitriev, M. and Rossi-Hansberg, E., 'The Spatial Diffusion of Technology', 2012, NBER Working Paper no. 18534, pp. 1-39, [Online] available at www.nber. org/papers/w18534.pdf, accessed on June 12, 2016.

5. Deephouse, D.L., 'Does Isomorphism Legitimate?', 1996, The Academy of Management Journal, vol. 39, no. 4, pp. 1024-1039.

6. DiMaggio, P.J. and Powell, W.W., 'The Iron Cage Revisited: Institutional Isomorphism and Collective Rationality in Organizational Fields', 1983, American Sociological Review, vol. 48, no. 2, pp. 147-160.

7. Dolowitz, D. and Marsh, D., 'Who Learns from Whom: A Review of the Policy Transfer Literature', 1996, Political Studies, vol. 44, no. 2, pp. 343-357. 
8. Frumkin, P. and Galaskiewicz, J., 'Institutional Isomorphism and Public Sector Organizations', 2004, Journal of Public Administration Research and Theory, vol. 14, no. 3, pp. 283-307.

9. Hsu, M.K. and Mesak, H.I., 'Government Programs and Diffusion of Innovations in Taiwan: An Empirical Study of Household Technology Adoption Rates', 2005, Journal of Nonprofit \& Public Sector Marketing, vol. 13, no. 1-2, pp. 91-110.

10. Jun, K.-N. and Weare, C., 'Institutional Motivations in the Adoption of Innovations: the Case of E-government', 2011, Journal of Public Administration Research and Theory, vol. 21, no. 3, pp. 495-519.

11. March, J.G., Schulz, M. and Zhou, X., The Dynamics of Rules. Change in Written Organizational Codes, Stanford: Stanford University Press, 2000.

12. Meyer, J.W., Boli, J., Thomas, G.M. and Ramirez, F.O., 'World Society and the Nation State', 1997, American Journal of Sociology, vol. 103, no. 1, pp. 144-181.

13. Pollitt, C., 'Clarifying Convergence: Striking Similarities and Durable Differences in Public Management Reform', 2001, Public Management Review, vol. 3, no. 4, pp. 471-491.

14. Wang, Q. and Guo, G., 'Yu Keping and Chinese Intellectual Discourse on Good Governance', 2015, The China Quarterly, vol. 224, pp. 985-1005.

15. Radaelli, C.M., 'Policy Transfer in the European Union: Institutional Isomorphism as a Source of Legitimacy', 2000, Governance: An International Journal of Policy, Administration and Institutions, vol. 13, no. 1, pp. 25-43.

16. Rogers, E.M., Diffusion of Innovations, New York: The Free Press, 1983.

17. Salomon, R. and $\mathrm{Wu}, \mathrm{Z} .$, 'Institutional Distance and Local Isomorphism Strategy', 2012, Journal of International Business Studies, vol. 43, no. 4, pp. 343-367.

18. State Council, 2001, Circular of the State Council Concerning Transmitting the Advice on Implementing the Reform of the Administrative Examination and Approval System, issued in 18 October 2001.

19. Weatherford, M.S., 'Measuring Political Legitimacy', 1992, American Political Science Review, vol. 86, no.1, pp. 149-166.

20. Yeloglu, H.O. and Sagsan, M., 'The Diffusion of E-government Innovations in Turkey: A Conceptual Framework', 2009, Journal of US-China Public Administration, vol. 6, no. 7, pp. 17-22.

21. Zhou, Y.M., 'Institutional Capital Theory: A Framework of Institutional Analysis of Institutional Capital Theory', 2004, Journal of Yunnan University, vol. 2, pp. 43-49.

22. Zhu, X., 'Mandate versus Championship: Vertical Government Intervention and Diffusion of Innovation in Public Services in Authoritarian China', 2014, Public Management Review, vol. 16, no. 1, pp. 117-139. 